\title{
A QUESTÃ̃ DA QUALIDADE DO MATERIAL DIDÁTICO DE MATEMÁTICA NA EDUCAÇÃO DE PESSOAS JOVENS E ADULTAS NO BRASIL
}

\author{
Lígia Menezes ${ }^{1}$ \\ Amadeu José Montagnini Logarezzi
}

\begin{abstract}
RESUMO
O presente texto trata-se de uma análise teórica que tem como enfoque os trabalhos de adaptação do livro espanhol "Matemáticas para Adultos" para o contexto brasileiro, de sua revisão e aplicação em uma sala de educação de pessoas jovens e adultas (EJA) - uma parceria do Núcleo de Investigação e Ação Social e Educativa (NIASE/ Universidade Federal de São Carlos) com o Centro de Investigação em Teorias e Práticas Superadoras de Desigualdades (CREA/Universidade de Barcelona). Essa análise é feita tendo como base a teoria da aprendizagem dialógica. Esta pesquisa buscou identificar e discutir as contribuições destes trabalhos para a produção de material que seja adequado para o ensino de matemática para pessoas jovens e adultas; particularmente para o trabalho de adaptação do livro. Ainda buscou identificar e discutir a importância da aprendizagem dialógica para a aprendizagem da matemática por pessoas jovens e adultas.
\end{abstract}

Palavras-chave: Aprendizagem dialógica; Educação de pessoas jovens e adultas; Matemática.

\section{INTRODUÇÃO}

O presente texto apresenta uma análise teórica que tem como enfoque os trabalhos de adaptação do livro espanhol "Matemáticas para Adultos" para o contexto brasileiro - uma parceria do Núcleo de Investigação e Ação Social e Educativa (NIASE/Universidade Federal de São Carlos) com o Centro de Investigação em Teorias e Práticas Superadoras de Desigualdades (CREA/Universidade de Barcelona) -, de revisão e de sua aplicação em uma sala de educação de pessoas jovens e adultas (EJA). O livro foi criado na Espanha na década de 80, com auxílio de participantes da Escola de La Verneda de Sant-Martí, na Cataluña, para a educação de pessoas jovens e adultas desta escola e de toda a Espanha.

A produção do livro original foi feita em conjunto com os educandos e as educandas. Devido ao fato de o livro ter sido produzido por e para pessoas jovens e adultas, ele tem um

\footnotetext{
${ }^{1}$ Licenciatura em Pedagogia, Universidade Federal de São Carlos (Ufscar). CEP: 13565-905 São Carlos - SP Brasil. End. el.: ligiapedago@yahoo.com.br

${ }^{2}$ Professor adjunto do Departamento de Engenharia de Materiais (Dema), Universidade Federal de São Carlos (Ufscar). CEP: 13565-905 São Carlos - SP - Brasil. End. el.: amadeu@ufscar.br
} 
conteúdo mais significativo para elas. Além de trazer conteúdos que precisam para dar continuidade aos estudos, esses são apresentados em situações que condizem com a etapa adulta de suas vidas e com situações que remetem ao mundo do trabalho em que estão inseridas. O livro como um todo busca valorizar o conhecimento adquirido pelos educandos e educandas ao longo da vida, pois a partir dos conhecimentos de natureza prática podem ser desenvolvidos os conhecimentos matemáticos abstratos. Sendo assim, o livro traz desafios e situações que motivam as pessoas jovens e adultas à aprendizagem e valoriza os conhecimentos que os educandos e as educandas adquiriram fora da escola.

Recentemente este livro foi cedido em concessão ao NIASE para realizar a tradução, adaptação e teste do material junto a salas de educação de pessoas jovens e adultas, visando a preparação de uma versão do livro para o contexto brasileiro.

Esses trabalhos foram feitos por uma equipe de pessoas que participaram do projeto de extensão da Universidade Federal de São Carlos (UFSCar) denominado “Aprendizagem Dialógica de Matemática e de Escrita - adaptação e criação de material”. A equipe do projeto era composta por estudantes e professores, de várias áreas do conhecimento e dos níveis de graduação e de pós-graduação, que revisava o trabalho de tradução e fazia adaptações de situações do contexto espanhol para situações do contexto brasileiro, tendo sempre como base as críticas e sugestões dos educandos e das educandas e o referencial da aprendizagem dialógica.

Os trabalhos tiveram início como parte do programa de extensão "Aprendizagem dialógica na educação de pessoas jovens e adultas", com financiamento do PROEXT/Sesu, realizado no primeiro semestre de 2005, tendo continuidade como projeto da Proex/UFSCar, no segundo semestre de 2005, necessitando de continuidade em 2006, quando foi terminada a adaptação. Em 2007, o trabalho está sendo centrado na revisão dos conteúdos de matemática e na revisão da tradução e redação, devendo ser enviado à editora até outubro. Os objetivos do projeto são: adaptar, testar e produzir materiais de ensino mais adequados para a aprendizagem adulta, com base no conceito de aprendizagem dialógica.

Todo este trabalho foi feito com base na aprendizagem dialógica, desenvolvida pelo CREA/Universidade de Barcelona como o guia teórico para compor uma proposta para o ensino de matemática. A aprendizagem dialógica é um conceito que foi elaborado pelo CREA com base na teoria de Paulo Freire sobre a dialogicidade e na de Habermas sobre a ação comunicativa. 
Em sua obra a "Pedagogia do Oprimido", Freire (1978) traz o conceito de dialogicidade e discorre sobre o diálogo igualitário. O autor ainda aponta as contradições entre opressores e oprimidos e a humanização e a desumanização. Para superar a situação de opressão, Freire (1978) propõe uma pedagogia libertadora, na qual os homens se empenham numa luta por sua libertação e essa libertação se dá através do pensar crítico, pois é transformando o saber resultante da ação em reflexão crítica que se constitui a consciência. Segundo o autor, somente o diálogo é capaz de gerar o pensar crítico. Para essa pedagogia, Freire (1978) propõe uma educação problematizadora que concebe as pessoas em suas relações com o mundo, que não vê as pessoas como seres vazios esperando para serem preenchidos de conteúdos e que seja guiada pela dialogicidade. $\mathrm{O}$ autor entende que o diálogo é fundamental para o processo de educar-se, por isso, a educação problematizadora afirma a dialogicidade e se faz dialógica.

Em sua obra Teoria da Ação Comunicativa, Habermas (1987) desenvolve sua própria teoria, que busca avanços sociológicos e a construção de uma nova possibilidade de racionalidade. Para chegar a esta teoria Habermas (1987) apresenta quatro tipos de ações que ele considera importantes para a racionalidade, são elas: ação teleológica, ação regulada por normas, ação dramatúrgica e ação comunicativa.

Nas palavras do autor, "A linguagem é um meio de comunicação que serve ao entendimento, ainda que os atores, ao entender-se entre si para coordenar suas ações, perseguem cada um determinadas metas" (HABERMAS, 1987-b, p. 145-146). Em sua teoria, Habermas nos deixa claro que todos os sujeitos são capazes de linguagem e ação, independente do nível de estudo, e que esses sujeitos têm possibilidade de entendimento através do diálogo, pois mediante ele, refletem.

A partir dos conceitos desenvolvidos por Habermas e por Freire, acima resumidos, e de várias experiências de sua aplicação em contextos escolares com vistas à melhoria do processo de ensino e aprendizagem, o CREA elaborou os sete princípios da aprendizagem dialógica, que são: diálogo igualitário, inteligência cultural, transformação, dimensão instrumental, criação de sentido, solidariedade e igualdade de diferenças, os quais podem ser sintetizados como segue:

- Diálogo igualitário: Respeito a todas as falas, igualmente. O que vale são os argumentos e não a posição de quem fala (idade, profissão, posição social, sexo, escolaridade, etc.).

- Inteligência cultural: Todas as pessoas têm uma inteligência cultural, que vão adquirindo ao longo da vida devido às muitas coisas que vão aprendendo e de diversas maneiras. 
Portanto, todas as pessoas, de quaisquer culturas, possuem capacidades para participar de um diálogo igualitário, ensinando e aprendendo.

- Transformação: A aprendizagem dialógica leva a uma transformação pessoal, pois ela valoriza as aprendizagens feitas ao longo da vida, e isso faz com que as pessoas se transformem quanto à sua auto-imagem e quanto à sua maneira de se pôr no mundo, produzindo mudanças nos entornos e nas relações com as pessoas.

- Dimensão instrumental: O diálogo e a reflexão possibilitam a aprendizagem de conhecimentos acadêmicos e instrumentais, e desenvolvem a capacidade de seleção e processamento de informação, habilidades fundamentais para compreender o mundo e estar no mundo como sujeito histórico.

- Criação de sentido: $\mathrm{Na}$ sociedade atual, com as constantes mudanças sociais, as pessoas passam a sentir que não são mais donas de suas próprias vidas e que são determinadas pelos sistemas. Isso faz com que as pessoas percam o sentido de porque estão no mundo. Por meio da aprendizagem dialógica, as pessoas passam a criar/recriar o sentido quando a interação entre as pessoas passa a ser conduzida por elas mesmas, pois cada pessoa se sente protagonista de sua própria existência.

- Solidariedade: Das interações e relações de respeito e de identificação vão se criando laços de solidariedade entre as pessoas, que passam a deixar de lado a competitividade para criarem laços de apoio mútuo e confiança.

- Igualdade de diferenças: As pessoas têm garantido o direito de serem diferentes e de exporem suas idéias, de serem respeitados em seus direitos e em suas diferenças culturais. "A verdadeira igualdade inclui o mesmo direito de toda pessoa viver de forma diferente" (FLECHA, 1997, p. 42). As diferenças culturais enriquecem o diálogo e potencializam as aprendizagens.

Tendo por base esses princípios, busca-se conceber uma aprendizagem dialógica, na qual o diálogo é uma importante ferramenta para a aprendizagem e se busca, através da comunicação e do diálogo, construir com os educandos e as educandas alternativas de aprendizagem de qualidade para todos e todas. Essa aprendizagem se dá através da interação entre sujeitos que produzem o diálogo igualitário e nela, todos aprendem, tanto educador quanto educando.

Como apoio ao referencial teórico central - a aprendizagem dialógica -, foram utilizados alguns teóricos que escreveram sobre a educação matemática e a educação matemática de pessoas jovens e adultas. Carraher, Carraher \& Schliemann (1990) discorrem sobre situações em que as pessoas aprendem matemática fora da sala de aula, mostrando que, através de suas experiências de trabalho, adquirem um conhecimento prático matemático. Os autores apresentam dados e análises de uma pesquisa feita com mestres-de-obras, que, na sua 
grande maioria, haviam se formado na profissão através de um treinamento informal no próprio trabalho. Através desta pesquisa, constatam que "o trabalho em uma profissão como a de mestre-de-obras, de baixo prestígio social, e na ausência de escolaridade pode resultar no desenvolvimento de estratégias gerais de solução de problemas, que recorrem ao esquema de proporcionalidade, característico do raciocínio formal” (p. 121).

$\mathrm{Na}$ perspectiva da aprendizagem dialógica as pessoas não são vistas como seres vazios a serem preenchidos, mas pessoas que possuem uma inteligência cultural, que é resultado de suas vivências culturais e práticas do mundo do trabalho. Aprender dialogando e valorizando os conhecimentos e o passado cultural que as pessoas trazem para a escola leva a uma transformação pessoal, pois as pessoas adquirem confiança em seus próprios conhecimentos e isso faz com que se alterem as relações com as outras pessoas e com o entorno. No caso da matemática, busca-se valorizar as diferentes formas de matematizar dos diferentes grupos culturais.

A partir dos trabalhos de D’Ambrosio (1975), surge no Brasil o Movimento de Etnomatemática, definida pelo autor como:

“(...) etno é hoje aceito como algo muito amplo, referente ao contexto cultural, e portanto inclui considerações como linguagem, jargão, códigos de comportamento, mitos e símbolos; matema é uma raiz difícil que vai na direção de explicar, de conhecer, de entender; e tica vem sem dúvida de techne, que é a mesma raiz de arte e de técnica." (p. 5).

Etnomatemática pode ser definido como o estudo da matemática que leva em conta o contexto cultural, as técnicas, habilidades e práticas utilizadas por distintos grupos culturais decorrentes do contexto em que vivem. Sempre buscando a compreensão da maneira particular como cada grupo cultural conhece, entende, explica e organiza seus conhecimentos matemáticos. É uma matemática que tem como embasamento uma concepção etnoantropológica de matemática.

Nesse sentido, a aprendizagem dialógica pode contribuir para que as pessoas aprendam a matemática escolar e para que façam novas aprendizagens a partir dos conhecimentos culturais e práticos que possuem.

Este trabalho tem por objetivo trazer para a discussão a questão da produção de material didático, no sentido de que o material a ser adotado possa fazer a diferença na hora do estudo e, para que este faça diferença, tem que ser de qualidade, ou seja, um material que apresente correção conceitual dos conhecimentos abordados, que traga situações que sejam 
condizentes com a realidade de vida e de trabalho das pessoas que irão utilizá-lo, que aborde os conteúdos necessários para a escolarização de uma forma clara e de fácil entendimento e que traga, ainda, desafios efetivos, exercícios que realmente motivem os estudantes e os ajudem a aprender. Portanto, é um trabalho que faz pensar uma produção de material didático para a educação de pessoas jovens e adultas que tenha essas qualidades. Por isso, este estudo pode trazer contribuições para essa área, pois possibilita pensar na produção de material a partir da perspectiva da aprendizagem dialógica, apontando para um importante diferencial de qualidade no material. De um lado, contribui para atenuar a escassez de material específico para o ensino de matemática para a EJA no Brasil, que traga situações do contexto jovem e adulto em que os educandos e educandas então inseridos. De outro, favorece a leitura crítica da realidade e a busca por sua transformação com base nas interações intersubjetivas.

\section{Métodos}

Foi feita uma conversa com a turma de EJA e com a educadora da sala, e foi apresentada a proposta de fazer o teste do livro "Matemáticas para Adultos", ficou combinado que em um dia da semana ao invés de ter aula normal, estudariam os conteúdos do livro traduzido e adaptado "Matemáticas para Adultos". Com isso, os educandos e as educandas estudariam os conteúdos matemáticos do livro junto com a educadora da sala e o/a monitor/a do projeto e poderiam contribuir para uma melhor adaptação do livro para o contexto da realidade brasileira.

O livro "Matemáticas para Adultos" é um livro adequado ao Ensino Médio. Embora não aborde todos os conteúdos dessa modalidade, certamente aborda os principais. É um material que procura trazer inovações, apresentando os conteúdos a partir de situações da vida cotidiana e da interdisciplinaridade. A divisão de seu conteúdo é feita em 12 capítulos: "Sistemas de numeração: os números naturais", “Os números inteiros”, "Divisão exata", "Os números racionais", "Potências e raízes", "Álgebra I", "Geometria I", "Proporções", "Geometria II", “Álgebra II", "Probabilidade e estatística" e "Matemática de conjuntos". Após o último capítulo há um apêndice de exercícios com exercícios do Exame Nacional do Ensino Médio (ENEM).

O trabalho de teste do livro na sala teve duração de três semestres e durante este período foram estudados os capítulos 1, 2 e 3 do livro adaptado. Portanto, os conteúdos estudados foram: "Sistemas de numeração: História dos sistemas de numeração; O conjunto N 
dos números naturais; $\mathrm{O}$ número zero; Leis de composição interna dos números naturais e suas propriedades; Contar em diferentes bases; Passagem de um número de qualquer base para base 10 e de base 10 para qualquer outra base; Operações em qualquer base; $\mathrm{O}$ funcionamento binário das calculadoras; $\mathrm{O}$ conjunto $\mathrm{Z}$ dos números inteiros como uma ampliação do conjunto $\mathrm{N}$ dos números naturais; Representação dos números inteiros; Adição e subtração em Z; Multiplicação em Z; Regra dos sinais; Propriedades da adição e multiplicação de números inteiros; Múltiplos e divisores; Regras da divisão; Números primos e compostos; Decomposição em fatores primos; Máximo divisor comum (M.D.C.) e mínimo múltiplo comum (M.M.C.); e Procedimentos para encontrar o M.M.C. e o M.D.C.

O teste do livro foi feito em uma sala de educação de EJA de $1^{\mathrm{a}}$ à $4^{\mathrm{a}}$ série, na escola PROAB - Santa Felícia (EMEI "Vicente da Rocha Keppe") do bairro Santa Felícia, na cidade de São Carlos, no estado de São Paulo (SP), onde havia uma média de 15 estudantes (o número não era exato pois sempre chegava um estudante novo ou algum deixava de freqüentar as aulas). As reuniões com a turma de EJA aconteciam uma vez por semana no horário da aula, que era das $19 \mathrm{hs}$ às $22 \mathrm{hs}$. Nestes encontros, eram estudados os capítulos do livro, resolvidos os exercícios e feita a correção dos mesmos em conjunto. Conforme a turma estudava os conteúdos do livro, eram feitas críticas e sugestões de como as adaptações do livro poderiam ser melhoradas.

A turma se sentava em um grande círculo para ler os capítulos da versão traduzida do livro (cada participante tinha sua própria cópia do capítulo) e para conversar sobre a matéria. Depois faziam os exercícios todos juntos. Algumas vezes se dividiam em grupos de quatro pessoas para resolver os exercícios. Após fazer os exercícios, iam à lousa para corrigi-los. Conforme iam estudando os capítulos, os educandos, as educandas e a educadora iam apontando as dificuldades que sentiam em entender as explicações do livro ou os enunciados dos exercícios e davam sugestões de como poderia ser feito para que eles entendessem melhor. Os apontamentos, as críticas e as sugestões feitos pela turma eram anotados e levados à equipe de adaptação do livro, que revisava o material levando em conta as opiniões dos participantes e das participantes. A partir destas críticas e sugestões foram feitas novas revisões do material para finalização do mesmo.

O trabalho de revisão e de adaptação consistia em analisar o trabalho de tradução e fazer adaptações de situações do contexto espanhol, de onde o livro é originário, para situações que levassem em conta a realidade da cultura brasileira, tendo sempre como base os apontamentos dos educandos e das educandas e o referencial da aprendizagem dialógica. 


\section{Resultados}

Os apontamentos feitos pela turma de EJA mostravam a necessidade de adequar o material à realidade brasileira, de substituir figuras que atrapalhavam o entendimento de conceitos, de melhorar a disposição das tabelas dos exercícios para facilitar a compreensão, além de apontar eventuais ambigüidades, pois um livro jamais está totalmente pronto, sempre sendo passível de aprimoramento.

Um exemplo de sugestão de adaptação é uma situação de um capítulo que tinha como tema o campeonato de futebol espanhol, o qual os educandos e as educandas sinalizavam que deveria ser adaptado para o campeonato brasileiro, pois as regras eram diferentes e isso confundia as pessoas por serem as regras do campeonato brasileiro parte de sua cultura. A partir deste apontamento, a equipe adaptou a situação para o campeonato brasileiro de futebol e isso implicou adaptar também os exercícios para condizerem com o conteúdo, pois a contagem dos pontos era diferente.

Em uma outra situação do livro, a qual trazia a representação de números inteiros, havia uma linha do tempo e um texto explicativo, o qual dizia que na linha do tempo o zero representava o nascimento de Cristo, sendo que à direita do zero ficavam os anos e os séculos posteriores a essa data, portanto, os anos depois de Cristo (d.C.), e que à sua esquerda ficavam os anos antes de Cristo (a.C.). Este assunto gerou muitas indagações, como por exemplo, por que começaram a contar depois do nascimento de Cristo? Quem fez o calendário? Como contavam os anos antes deste calendário e se contavam? Existia a escrita antes de Cristo? Como ela era? Antigamente as pessoas contavam de traz para frente? Como faziam para saber quanto tempo havia se passado? E hoje, como se faz para saber quanto tempo se passou, por exemplo, de - 609 até 2005? A partir destas perguntas surgiu a discussão de como as pessoas contavam os dias antes do surgimento do calendário, como faziam contas e como faziam anotações e o resultado dessa discussão foi a troca de muitos conhecimentos e aprendizado sobre o tema. Como por exemplo, que quando não havia o calendário, havia outras formas de contar os dias, como contar as luas, ou contar nós feitos em cordas. Que para fazer anotações, quando não havia a escrita, eram usados desenhos representativos.

Um outro exemplo a destacar foi quando os educandos e as educandas prepararam uma aula para os/as participantes da Atividade Curricular de Integração entre Ensino Pesquisa e Extensão (ACIEPE) - Aprendizagem Dialógica na Educação de Jovens e Adultos - 
oferecida pela UFSCar, que visitaram a sala de educação de pessoas jovens e adultas. Essa aula foi de um assunto que estava no capitulo 1 do livro, o qual os educandos e as educandas já haviam estudado. Os assuntos da aula eram "A História dos Números" e "A Numeração Maia”. Para realizar esse trabalho, eles e elas se prepararam estudando e planejando entre si como seria a aula. Quem coordenou os trabalhos foram os próprios educandos e educandas, com o objetivo de mostrar como é que se trabalhava a aprendizagem dialógica em matemática nesta sala de educação de pessoas jovens e adultas. O fato de os/as participantes da ACIEPE estarem aprendendo com os educandos e as educandas pareceu uma importante transformação para os dois grupos da interação.

Essas adaptações foram feitas pensando em adequar o livro à realidade brasileira, por acreditar que por ser um livro destinado à educação de pessoas jovens e adultas do Brasil, seus exemplos deveriam remeter ao contexto brasileiro, favorecendo a identificação das educandas e dos educandos com os estudos e a atribuição de sentido a eles.

\section{Considerações finais}

Para que a educação de pessoas jovens e adultas seja de qualidade, ou seja, para que haja uma educação que aborde os conteúdos necessários para o avanço da escolarização e que possibilite a transposição do saber prático em saber acadêmico, existem dois pontos que precisam ser trabalhados que são: a qualificação da prática dos educadores e das educadoras e o material didático utilizado.

Para que os educadores e as educadoras possam fazer um bom trabalho, é preciso receber cursos que lhes dêem ferramentas para trabalhar os conteúdos. No caso da matemática, muitos educadores e educadoras não se sentem à vontade em trabalhar a matemática em sala de aula por não se sentirem preparados, por isso é essencial que eles e elas tenham uma capacitação. Ao estar sempre em contato com os conteúdos da matemática os educadores e as educadoras começam a sentir mais segurança em trabalhá-los.

O material didático também é um outro fator que pode contribuir para a melhora da qualidade da educação de pessoas jovens e adultas, pois um material específico para essa modalidade de ensino, que leve em conta a realidade dos educandos e das educandas, pode resultar em uma aprendizagem mais significativa e efetiva. Muitas vezes, os materiais utilizados são cartilhas ou livros utilizados na educação infantil, os quais trazem, como no caso do ensino da matemática, situações e exemplos infantilizados, o que não é adequado, já que se trata de pessoas jovens e adultas. 
Um material que traga situações e exemplos do mundo do jovem e do adulto e do contexto do trabalho pode contribuir para uma aprendizagem mais significativa da matemática, ou seja: na escola, a resolução de problemas tem objetivos diferentes dos que motivam as pessoas a resolverem os problemas de matemática fora da sala de aula, os quais têm mais significado para as pessoas, pois fora da sala de aula a matemática é parte de atividades do cotidiano, como compra, venda, construção civil, costura etc. $\mathrm{Na}$ escola, a motivação para fazer as contas é acertar, enquanto na vida cotidiana, as mesmas contas são feitas para comprar, vender, calcular quantidade de material utilizado na obra, distâncias etc. E foi nesse sentido que, com base na aprendizagem dialógica e na etnomatemática, este trabalho propiciou um material didático que, acredita-se, possa vir a ser importante para o desenvolvimento da EJA no Brasil, contribuindo para o potencial de transformação social desse contexto educativo.

\section{Referências}

CARRAHER, T.; SCHLIEMANN, A. L.; CARRAHER, D. "Na vida dez, na escola zero". $4^{\circ}$ ed. São Paulo, Editora Cortez,1990.

D`AMBrosio, U. Etnomatemática. São Paulo, Editora Ática, 1990. (Série Fundamentos 74).

FLECHA, R. Compartiendo Palabras: el aprendizaje de las personas adultas através del diálogo. Barcelona: Paidós Studio, 1997.

FREIRE, P. Pedagogia do Oprimido. 6a edição. Rio de Janeiro, Editora Paz e Terra, 1978.

HABERMAS, J. Teoria de la Acción Comunicativa. Vol. 1. Racionalidad de la acción y racionalización social. Madrid. Taurus, 1987 (b). 